\title{
ASSESSING THE EFFECT OF NATURAL ATTENUATION ON SEWAGE SLUDGE USING FABA BEAN (VICIA FABA) TEST AND GC-MS ANALYSIS
}

\author{
El-Shaboury, G. A. ${ }^{*}$ - GHRAMH, H. A. ${ }^{1,2,3}$ - IBRAhIM, E. H. ${ }^{1,2,4}-$ HAROUN, S. A. ${ }^{5}$ \\ ${ }^{1}$ Biology Department, Faculty of Science, King Khalid University, P.O. Box 9004, Abha 61413, \\ Saudi Arabia
}

${ }^{2}$ Research Center for Advanced Materials Science (RCAMS), King Khalid University, P.O. Box 9004, Abha 61413, Saudi Arabia

${ }^{3}$ Unit of Bee Research and Honey Production, Faculty of Science, King Khalid University, P.O. Box 9004, Abha 61413, Saudi Arabia

${ }^{4}$ Blood Products Quality Control and Research Department, National Organization for Research and Control of Biologicals, Cairo, Egypt

${ }^{5}$ Botany Department, College of Science, Kafr El-Sheikh University, Kafr El-Sheikh, Egypt

*Corresponding author

e-mail: Gamal3003@yahoo.com; phone: +966-56-276-2992; fax: +966-17-241-8205

(ORCID: http://orcid.org/0000-0003-1040-2049)

(Received 25 $5^{\text {th }}$ Dec 2020; accepted $18^{\text {th }}$ Mar 2021)

\begin{abstract}
Sewage sludge (SS) is the final product of wastewater treatment its accumulation can cause serious environmental problems; however, it may be used as agricultural fertilizer. Our objective was to evaluate the effect of natural attenuation on SS by studying the cytotoxicity and genotoxicity potential of different concentrations of SS extract and soil mixtures using the Vicia faba L. test, and to study the microbiological biodiversity and presence of toxic furans and dioxins during natural attenuation. Cytological investigation of treated $V$. faba roots after 12 months of natural attenuation revealed that the percentage of different types of mitotic abnormalities increased with the concentration of raw SS from induced DNA damage in $V$. faba roots. However, this effect declined during the attenuation periods. Although after the natural attenuation period, significant effects were detected for the highest tested concentration (100\% SS). Nine different bacterial colonies were observed in SS, but only three colonies remained after 12 months. Moreover, Gas Chromatography-Mass Spectrometry analysis showed that the concentrations of toxins were reduced during the natural attenuation periods. Therefore, we concluded that raw SS should not be used as soil fertilizer without detoxification, and its toxic potential must be formally assessed.
\end{abstract}

Keywords: biosolids, detoxification, chromosomal aberration, cytotoxicity, genotoxicity

\section{Introduction}

Sewage sludge refers to the residual, semi-solid material produced as a secondary product during sewage treatment of municipal or industrial wastewater. It is mainly composed of organic matter; nutrients (nitrogen and phosphorus) and toxic contaminants (Gray, 2010). Due to its high organic and nutrients contents that are necessary for the plant growth, SS is considered a good fertilizer in agricultural areas. However, raw sewage sludge may contain toxic contaminants and pathogenic microorganisms; thus, specific treatment is required for raw SS before use in agriculture to neutralize toxins and avoid direct exposure to human pathogenic microorganisms 
(Clarke and Smith, 2011). Natural attenuation depends on natural processes that decrease or "attenuate" toxicity and concentrations of contaminants in soil. To ensure the effectiveness of natural attenuation, the conditions are monitored. Natural attenuation involves chemical, physical and biological processes that normally occur in the environment (Mazzeo et al., 2015)

Allium cepa is considered a biological marker for cellular and DNA damages because it assesses the efficiency of environmental decontamination developments (Mazzeo et al., 2010; Souza et al., 2013). Also, Fels et al. (2015) employed Vicia faba micronucleus (MN) test to assess the mutagenicity of the raw sewage sludge polluted with hexavalent chromium and composts of this residue mixed with palm waste (mixture A: 1/3 sludgep2/3 palm waste and mixture B: $1 / 2$ sludgep $1 / 2$ palm waste).

Vicia faba micronucleus (MN) test assesses genotoxicity and chromosomal aberrations. It is commonly used to assess the genotoxicity of organic and inorganic compounds from soils (Marcato-Romain et al., 2009), manufacturing sewages and wastewater (Shukla et al., 2007), organic substances such as SS or composts (Kapanen et al., 2013), and from water (Monarca et al., 2003). Furans and dioxins are toxic organic components of SS (Mazzeo et al., 2015). Since furan is highly volatile in nature, the most common technique for the analysis of this substance is headspace sampling (Crews and Castle, 2007). Furans have also been investigated using a solid-phase microextraction (SPME) technique in combination with GC-MS (Gas ChromatographyMass Spectrometry) (Crews and Castle, 2007; Mesias and Morales, 2014).

In this study, the $V$. faba root-micronucleus test was used to evaluate cytotoxicity and genotoxicity induced by raw SS and composts of SS mixed with soil for different time periods; furthermore, microorganisms biodiversity was studied through different natural attenuation periods, and toxins were detected using GC-MS analysis, in order to assess the co-composting effect to remove the toxicity.

\section{Materials and methods}

\section{Sample preparation}

Samples of anaerobic SS were collected from a wastewater treatment plant (WWTP), located in the municipality of Abha (Saudi Arabia), that receives only effluents from domestic sewage, three samples were taken over three weeks $20 \mathrm{~kg}$ each week and were dried under shade for 10-15 days in the greenhouse of King Khalid University, Abha (Saudi Arabia). The SS samples were mixed with a reference soil (collected from a depth of $0-20 \mathrm{~cm}$ from the adjacent agricultural fields) in proportions of $10 \%, 25 \%$ and $50 \%$ SS.

\section{Detoxification of SS through monitored natural attenuation}

Samples containing 10\%, 25\%, 50\% and 100\% raw SS were located in microperforated bags with openings that were $0.5 \mathrm{~mm}$ in diameter and $1 \mathrm{~cm}$ apart. Each bag was filled with $4 \mathrm{~kg}$ of each sample. The bags were buried in the area surrounding the greenhouse in holes with a maximum depth of $30 \mathrm{~cm}$ to permit interactions between the samples and the external environment and to avoid significant temperature fluctuations for 6 and 12 months. The greenhouse is an ideal location for this kind of experiment because it is free of waste products, which could contaminate the samples. Moreover, it prevente the distribution of contaminants. 


\section{Preparation of SS aqueous extract and treatment}

For each sample, $125 \mathrm{~g}$ (equivalent dry weight) of each sample were dissolved in $500 \mathrm{ml}$ distilled water with steering for $10 \mathrm{~min}$ and incubated with shaking at $22{ }^{\circ} \mathrm{C}$ for 3 days as described by ABNT (2004). Then, the solutions were filtered through a $0.45-\mathrm{mm}$ pore Whatman filter papers to obtain extracts containing water-soluble substances; the supernatant was collected and stored at $4{ }^{\circ} \mathrm{C}$ until use.

Vicia faba seedlings were prepared according to Marcato-Romain et al. (2009). Dry $V$. faba seeds were soaked for $6 \mathrm{~h}$ in ultrapure water. Seed coats were removed, and seeds were placed on layers of wet cotton to germinate. After 3 days, germinated seeds with primary roots that were approximately $2 \mathrm{~cm}$ in length were selected for the treatment assay. The primary root tips were removed to stimulate the growth of secondary roots. Five independent replicates were made for each test. These germinated seedlings were treated for 3 days with the aqueous extract of the soil only, ultrapure water (negative control), $10 \mathrm{mg} / \mathrm{L}$ methyl methanesulfonate (Sigma-Aldrich, mutagenic agent) (positive control), SS $100 \%$, SS $50 \%$, SS $25 \%$ and SS $10 \%$ SS mixed with soil for natural attenuation periods $0,6,12$ months, all tests were performed in duplicate.

The germinated treated $V$. faba secondary roots were collected and fixed in a mixture of ethanol and acetic acid $(3: 1 \mathrm{v} / \mathrm{v})$ as a fixative for $6 \mathrm{~h}$ at room temperature. Next, the roots were washed with distilled water, and then kept in $70 \%$ ethanol at $4{ }^{\circ} \mathrm{C}$ until use. The fixed roots were stained using the Fulgen squash technique, and then mitotic division slides were prepared. Genotoxic effects were estimated in meristematic cells of $V$. faba which presented different types of chromosomal aberrations (e.g., bridges, losses, breakage, and adherence) and nuclear abnormalities (e.g., budding, lobulated nuclei, and binucleated cells). Cytotoxicity was evaluated through recording the changes in the mitotic index, and the mutagenic potential was evaluated through micronuclei recorded of F1 cells and chromosomal breaks in meristematic cells. These parameters were observed under a light microscope, and 10 slides per treatment were assessed with 500 cells were examined per slide. The efficiency of the natural attenuation was estimated by comparing the recorded results in 5 individuals for each treatment along with the negative control using a two-way ANOVA.

\section{Microbiological biodiversity}

To evaluate the diversity of the microorganisms existing in the SS and the soil, $0.5 \mathrm{~g}$ of each sample (100\% SS and soil as control) was dissolved in $100 \mathrm{ml}$ of sterilized saline solution after 0,6 , and 12 months of monitored natural attenuation; $20 \mathrm{ul}$ of this solution was spread with an inoculation loop, onto Petri dishes in duplicated containing blood agar, SS agar, and MacConkey agar in duplicate. The Petri dishes were incubated at $35^{\circ} \mathrm{C}$. The plates were observed after 4 days. The colony-forming units (CFUs) was used to record the germinated microorganisms colonies found in each sample.

\section{Detection of furans and dioxins using GC-MS analysis}

Furans and dioxins, as example toxins, in the SS and the soil (100\% SS and soil as controls) were detected using GC-MS as described by El-Shaboury et al. (2017). The GC-MS analyses were performed using the GC Shimadzu system QP2010 with a gas chromatograph interfaced with a mass spectrometer with a fused Elite-1 silica capillary 
column. The GC-MS conditions were as follows: carrier gas: Helium with constant flow $(1.0 \mathrm{ml} / \mathrm{min})$, Injector temperature of $250{ }^{\circ} \mathrm{C}$, Split Ratio $=2$. The over temperature programme was as follows: Initial temperature of $40{ }^{\circ} \mathrm{C}$ (with a 1 min delay), increase temperature from $40{ }^{\circ} \mathrm{C}$ to $150{ }^{\circ} \mathrm{C}$ at a rate of $10{ }^{\circ} \mathrm{C} / \mathrm{min}$ (with no delay), then increase temperature from $150{ }^{\circ} \mathrm{C}$ to $280{ }^{\circ} \mathrm{C}$ at a rate of $5{ }^{\circ} \mathrm{C} / \mathrm{min}$ for $5 \mathrm{~min}$ (with a delay); the total runtime $=30 \mathrm{~min}$. The Injected Volume of the aqueous extract of SS, which contain the water-soluble substances, was $1 \mu \mathrm{L}$, and the Interface Temperature $=280$ ${ }^{\circ} \mathrm{C}$. Interpretation of the mass spectrum GC-MS was performed with the NIST Ver. 2.1 MS data library (Joulain and Koenig, 1998). Finally, dioxins and furans were quantified at different retention times for each sample.

\section{Data analyses}

The data were examined for their homogeneity of variance and normality of distribution, and when necessary, the data were log-transformed before a two-way analysis of variance (ANOVA) was performed. Significant differences in the Mitotic Index, Mutagenic Alterations, Genotoxic Alterations, Micronuclei in F1 cells of Vicia faba cells treated with different concentrations of raw sewage sludge among different months were evaluated using a two-way ANOVA. Statistica 7.1 was used to process all the statistical analyses (Statsoft, 2007).

\section{Results}

\section{Cytotoxicity and mutagenic alteration of treated $\mathrm{V}$. faba seedlings}

For evaluating the recommended natural attenuation period for SS-soil mixture to be used safely as soil fertilizer; the mitotic index, genotoxicity, cytotoxicity, and F1 cells micronuclei were recorded in $V$. faba roots treated with extracts of different concentration of SS mixed with soil. Sewage sludge different concentrations were appointed to significantly $(P<0.001)$ change all the parameters (Table 1$)$. The application of SS significantly $(P<0.001)$ increased the mitotic index.

Generally, the mitotic index was increased with time prolonged throw natural attenuation periods in all examined concentrations of SS. There was complete inhibition for seed germination for seeds treated with aqueous extract of $100 \%$ SS at 0 months (raw SS); however, for the same concentration of SS, a low mitotic index was recorded (34.3\%) after 6 months of natural attenuation. The highest mitotic index was recorded for $50 \%$ SS concentration after 12 months (50.17\%) comparing with the positive control.

Genotoxicity, cytotoxicity and micronuclei in F1 cells of $V$. faba were induced owing to SS treatment for different natural attenuation periods, including different types of chromosomal abnormalities (e.g., delays, chromosomal bridges, chromosomal breaks, and lagging and unoriented chromosomes) as shown in Figure 1 and Table 1. The highest genotoxicity (11.0 and 9.95) were found for 100\% and 25\% SS concentrations, respectively, after a 6-month natural attenuation period, but the lowest genotoxicity (2.06) was found for 50\% SS after 12 months. Owing to the high toxicity of raw SS (0month treatment), high percentages of stickiness as chromosomal abnormalities across mitotic division were recorded as severe to moderate stickiness (Fig. 1). Genotoxicity was significantly reduced with different concentrations of SS-soil mixture after 12 months than other treatments. 


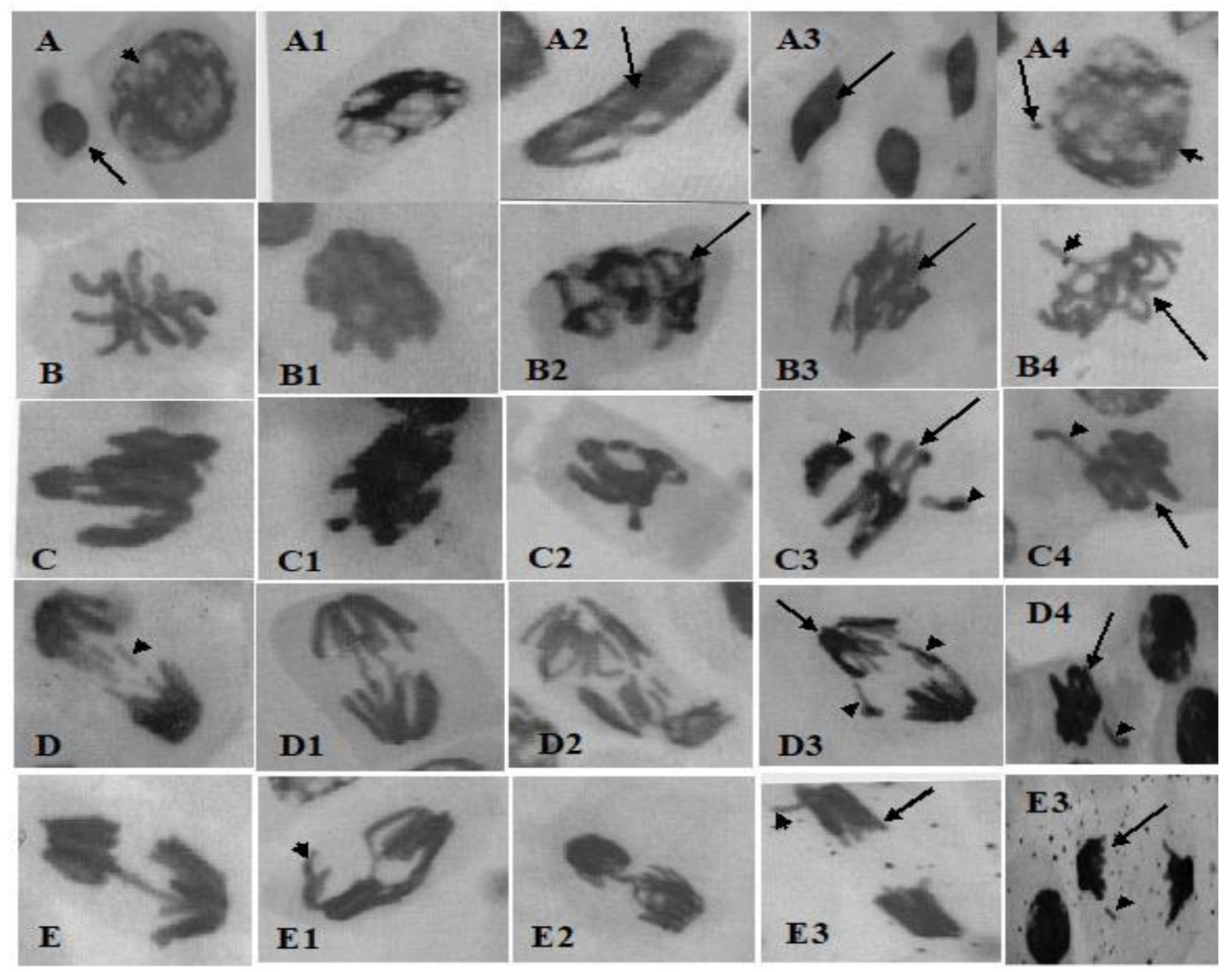

Figure 1. A: Arrow (micro nuclei) arrow head (normal interphase); A1: Vacuolated nuclei; A2: Stickiness prophase; A3: hard stickiness interphase; A4: Arrow (very small micro nuclei) arrow head (normal interphase); B: Sticky chromosomes in late prophase; B1: Hard stickiness prophase; B2: Stickiness prophase; $B 3$ \& B4 Partially stickiness prophase with delay; $C$ \& C1 Hard stickiness metaphase; C2: Partially stickiness metaphase; C3: Sticky chromosomes in metaphase arrow head (unoriented chromosomes with pro-micro nuclei); C4: Metaphase with delay; D: Anaphase with chromosome breaks; D1: Multi Bridge anaphase; D2: Disturbed anaphase with pro-micro nuclei; D3: Arrow (anaphase) arrow head (lagging chromosomes);

D4: Arrow (stickiness metaphase) arrow head (pro-micro nuclei); E: Late anaphase with chromosome bridge; E1: Early telophase with chromosome bridge; arrow head (pro-micro nuclei); E2: Telophase with chromosome bridge; E3: Telophase with chromosome delay; E4: Arrow (Telophase) arrow head (chromosome breaks)

Most of the induced chromosomal abnormalities were chromosomal losses, chromosomal breaks, lagging and unoriented chromosomes (Fig. 1). Completed division lead to micronuclei, which appeared as DNA damage; the percentage of micronuclei recorded in F1 cells are presented in Table 1. The lowest percentage of micronuclei were $(0.05$ and 0.06$)$ were found at $10 \%$ and $25 \%$ SS concentrations, respectively, after 0 months. The highest percentage of micronuclei (3.43) was recorded for $100 \%$ SS treatment after 6 months.

\section{Microbial diversity in SS}

To determine the microbial toxicity in SS, microbial biodiversity was evaluated for $100 \%$ SS after each natural attenuation period by inoculating different types of media. 
The raw SS (0 months) had a high diversity of microorganisms with six different colonies found. The diversity of microorganisms decreased with increased natural attenuation periods; after 6 months of natural attenuation, there were 5 different colonies, including two new colony types, but after 12 months, the analysis showed only three colonies including one new colony type. Figure 2 shows the microbial succession observed during the different periods of natural attenuation compared with microorganisms germinated using the reference soil.

Table 1. Variations in Vicia faba cells treated by different concentrations of raw sewage sludge after different periods of natural attenuation

\begin{tabular}{|c|c|c|c|c|c|c|c|c|}
\hline \multirow{2}{*}{ Parameters } & \multirow{2}{*}{ Month } & \multicolumn{7}{|c|}{ Treatments } \\
\hline & & Soil & $\mathrm{NC}$ & $\mathbf{P C}$ & SS_10\% & SS_25\% & SS_50\% & SS_100\% \\
\hline \multirow{4}{*}{ Mitotic index } & $\mathbf{0}$ & $31.33 \pm 0.33$ & $35.82 \pm 0.54$ & $37.00 \pm 0.58$ & $37.89 \pm 0.56$ & $36.00 \pm 0.58$ & $35.82 \pm 0.13$ & $0.0 \pm 0.0$ \\
\hline & 6 & & $45.00 \pm 0.58$ & $43.23 \pm 0.87$ & $44.00 \pm 0.58$ & $46.33 \pm 0.89$ & $45.00 \pm 0.58$ & $34.31 \pm 4.11$ \\
\hline & 12 & & $44.37 \pm 0.87$ & $47.67 \pm 0.88$ & $47.41 \pm 0.89$ & $49.33 \pm 0.88$ & $50.17 \pm 1.11$ & $46.00 \pm 1.15$ \\
\hline & \multicolumn{8}{|c|}{$\mathbf{F}_{\text {Month }}=152.4 * * *, d f=2 ; \mathbf{F}_{\text {Sanple }}=375.8 * * *, d f=6 ; \mathbf{F}_{\text {Month } \times \text { Sample }}=126.6 * * *, d f=12$} \\
\hline \multirow{4}{*}{ Mutagenic alterations } & $\mathbf{0}$ & $0.85 \pm 0.15$ & $0.49 \pm 0.00$ & $16.42 \pm 0.30$ & $0.75 \pm 0.01$ & $1.05 \pm 0.05$ & $1.39 \pm 0.04$ & $0.0 \pm 0.0$ \\
\hline & 6 & & $0.93 \pm 0.07$ & $8.39 \pm 0.87$ & $0.89 \pm 0.11$ & $2.42 \pm 0.30$ & $0.49 \pm 0.29$ & $3.00 \pm 0.00$ \\
\hline & 12 & & $0.07 \pm 0.07$ & $11.63 \pm 0.32$ & $0.85 \pm 0.16$ & $0.08 \pm 0.08$ & $0.12 \pm 0.12$ & $1.00 \pm 0.00$ \\
\hline & \multicolumn{8}{|c|}{$\mathbf{F}_{\text {Month }}=33.3^{* * *}, d f=2 ; \mathbf{F}_{\text {Sample }}=961.0 * * *, d f=6 ; \mathbf{F}_{\text {Month } \times \text { Sample }}=54.6 * * *, d f=12$} \\
\hline \multirow{4}{*}{ Genotoxic alterations } & $\mathbf{0}$ & $3.93 \pm 0.58$ & $2.70 \pm 0.29$ & $9.39 \pm 0.31$ & $4.98 \pm 0.26$ & $8.50 \pm 0.29$ & $8.03 \pm 0.22$ & $0.0 \pm 0.0$ \\
\hline & 6 & & $5.46 \pm 0.29$ & $14.56 \pm 0.29$ & $5.49 \pm 0.29$ & $9.95 \pm 0.06$ & $8.42 \pm 0.30$ & $11.00 \pm 0.00$ \\
\hline & 12 & & $3.00 \pm 0.58$ & $11.42 \pm 0.30$ & $2.93 \pm 0.07$ & $2.00 \pm 0.58$ & $2.06 \pm 0.06$ & $5.13 \pm 0.13$ \\
\hline & \multicolumn{8}{|c|}{$\mathbf{F}_{\text {Month }}=331.8^{* * *}, d f=2 ; \mathbf{F}_{\text {Sample }}=360.4^{* * *}, d f=6 ; \mathbf{F}_{\text {Month } \times \text { Sample }}=90.7^{* * *}, d f=12$} \\
\hline \multirow{4}{*}{$\begin{array}{l}\text { Micronuclei in F1 } \\
\text { cells }\end{array}$} & $\mathbf{0}$ & $0.15 \pm 0.15$ & $0.37 \pm 0.01$ & $8.00 \pm 0.00$ & $0.05 \pm 0.03$ & $0.06 \pm 0.06$ & $3.28 \pm 0.11$ & $0.0 \pm 0.0$ \\
\hline & 6 & & $0.86 \pm 0.15$ & $7.52 \pm 0.29$ & $1.48 \pm 0.29$ & $1.53 \pm 0.29$ & $1.14 \pm 0.14$ & $3.43 \pm 0.30$ \\
\hline & 12 & & $0.12 \pm 0.12$ & $10.36 \pm 0.32$ & $1.04 \pm 0.04$ & $0.91 \pm 0.09$ & $0.85 \pm 0.15$ & $0.95 \pm 0.05$ \\
\hline & \multicolumn{8}{|c|}{$F_{\text {Month }}=21.8 * * *, d f=2 ; F_{\text {Sample }}=976.9^{* * *}, d f=6 ; F_{\text {Month } \times \text { Sample }}=48.0 * * *, d f=12$} \\
\hline
\end{tabular}

NC: negative control, PC: positive control, $F$-values represent the two-way ANOVA, $d f=$ degrees of freedom, $* * *: P<0.001$

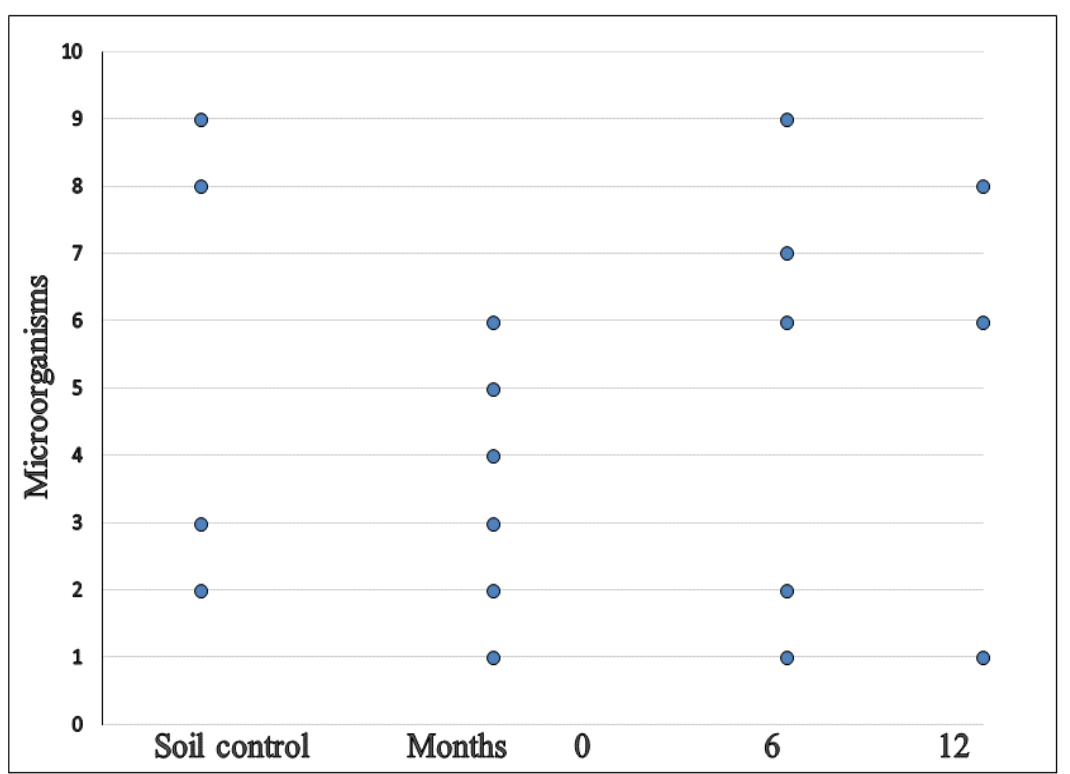

Figure 2. Microorganisms progression observed during different periods of natural attenuation of $100 \%$ SS Where 1 to 9 refers to different types of microorganisms colonies which scored using scoring colony-forming units 


\section{Detection of furans and dioxins}

GC-MS analysis for $100 \%$ SS was used to assess the toxicity level of furans and dioxins, which are some of the toxins found in SS (Table 2). Different types of furan were detected at different levels; there was a high level of 2-Pentyl furan in raw SS at 0 months but after 6- and 12-months natural attenuation period levels were low. 2-\{[1(Furan-2-yl) ethyl] amino ethan-1-ol was detected in raw SS and after 6 months but was not detected after 12 months of natural attenuation. N-Benzoyl-9-(2,3,5-tri-Obenzyl pento furanosyl)-9H-purin-6-amine was only detected at a very low level in the initial sample (raw SS). Furanon dihydro-5-tetradecyl was also detected at a high level in raw SS but decreased to a moderate level at 6 months sample and was not detected at 12 months sample. Generally, the types of furans detected decreased throughout the natural attenuation periods. No dioxins were recorded in all examined samples.

Table 2. Toxin progression observed during different periods of natural attenuation of $100 \%$ SS using GC-MS analysis. (There are three levels of detected toxins high level $(+++)$, moderate level $(++)$, low level $(+))$

\begin{tabular}{c|c|c|c}
\hline \multirow{2}{*}{ Dioxins and furans } & \multicolumn{3}{c}{ Samples } \\
\cline { 2 - 4 } & Initial sample (raw SS) & 6-month sample & 12-month sample \\
\hline Dioxins & Not detected & Not detected & Not detected \\
\hline Furans & +++ & + & + \\
\hline 2-pentyl furan & ++ & ++ & Not detected \\
\hline $\begin{array}{c}\text { N-benzoyl-9-(2,3,5-tri-O-benzyl pento } \\
\text { furanosyl)-9H-purin-6- amine }\end{array}$ & + & Not detected & Not detected \\
\hline Furanon dihydro-5-tetradecyl & +++ & + & Not detected \\
\hline
\end{tabular}

\section{Discussion}

\section{Assessment of the effects of SS on Vicia faba}

There is no germination for Vicia faba seeds treated with $100 \%$ SS aqueous extracts at 0 months, indicating that the treatment with raw SS without any natural attenuation period was considered highly toxic to the test organism, thus excluding the valuation of the cytotoxic, mutagenic and genotoxic potential of this samples. Walter et al. (2006) recorded similar results by regarding seeds germination of Lepidium sativum L. treated with SS. In our study, no any other inhibition recorded in seed germination for the other treated samples.

Assessment of the cytotoxicity in seeds germinated directly in SS after 6 months period at $100 \%$ SS mitotic cell division of Vicia faba was inhibited comparing with the negative control by regarding the mitotic index values which it was $35.82 \%$ decreased to $34.31 \%$ which recorded as lowest mitotic index this is may be due to the toxicity still exist even after 6 months of natural attenuation which altered the cell division reflected as high percentage of stickiness phases across all phases of mitotic cell division (Fig. 1). Similar effect observed by the treatment with $50 \%$ SS after 0-month period where the mitotic index was $35 \%$ compared with the other treatments after the same period. Table 1, showed that the cytotoxicity was decreased through natural attenuation periods of the SS concentrations which reflected as increasing in mitotic index, this confirms the efficiency of this process for inhibiting the toxicity effect of raw SS. Similar results 
obtained by Mazzeo et al. (2015) where they evaluate the cytotoxicity effect on A. cepa seeds germinated in different concentration of SS at different periods.

Concerning genotoxic potential, a substantial frequency in cellular alterations was recorded in the association of 10,25 and 50\% concentrations after a period of 0 months of natural attenuation and for concentrations of 25, 50 and 100\%; after 6 months of natural attenuation Table 1. Where the 100\% SS extract after 6 months treated seeds, severe genotoxic effect induced on the cells as also after 12 months, the 100\% SS (raw SS) still induced highly significant genotoxic effects, confirming that the contaminants responsible for genotoxic potential in SS are still active even after 12 months of natural attenuation. Our results regarding the genotoxic potential of SS indicated that; $100 \%$ SS cannot be considered an applicant material for use as a soil reconditioner due to its persistent toxicity recorded in our study. Therefore, based on our results, SS/soil mixtures are more convenient for use in agriculture. These results agree with Walter et al. (2006); they confirmed the harmful effect of raw SS in agriculture by regarding (Lepidium sativum L.) seeds germination.

Significant mutagenic effects were recorded on the mitotic division for the tested organism (Vicia faba) of 25,50\% after a period of 0 months of natural attenuation indicating that raw SS cannot be used in agriculture without natural attenuation. 100\% SS after 6 and 12 months of natural attenuation also cannot be used as a soil fertilizer because SS without any soil mixture induced significant and sever mutagenic effect for the tested plant (Table 1). 50\% SS without any natural attenuation period induced the formation of Micronuclei. Also, after 6 months of natural attenuation period 25, 100\% SS also induced the formation of micronuclei (Fig. 1). The recorded significant results for F1 cells showed that the damage recorded in Vicia faba cells was transferred to and stable in cells of the F1 region. Thus, even at lower concentrations, the SS samples were inducing the destruction of the genetic material of the meristematic cells of the test organism. These data support that $100 \%$ SS cannot be detoxified compared with the mixture of soil/SS.

From the obtained above results, natural attenuation period for 12 months appeared as the excellent period for degradation of the most mutagenic and toxic substances existing in the studied SS (see Fig. 1; Table 1). Genotoxicity can be induced also in Allium cepa due to exposure to SS which reported by many authors, for example, Srivastava et al. (2005); they recorded mitotic index reduce and significant chromosomal aberrations frequency induced by SS aqueous extract treatment in India. Caritá (2007) also study genetic damage induced in A. cepa due to the treatment by aqueous extract of SS which collected from five WWTPs of Sao Paulo (Brazil). Furthermore, highly genotoxic effects in seeds of $A$. cepa exposed to biosolids as raw materials were recorded by Christofoletti et al. (2012).

The mutagenic and genotoxic effects recorded in our study may be due to the existence of toxic substances as cresol, also due to the synergistic effects of the main components of SS. According to ATSDR (2008) who studied in vitro tests in human and animals which confirmed that cresols can effect on DNA inducing genotoxicity. Our results can confirm that the reduction of the toxicity effect of SS through natural attenuation periods with soil mixture.

\section{Microbiological biodiversity of SS}

In our study on microorganisms biodiversity, we used three different types of media to help many different types of microorganisms to germinate. About nine different microorganisms colonies were recorded in the examined sample (100\% SS and soil 
control) regarding the reference soil the highest rates of microorganisms biodiversity was six different shapes of microorganisms colonies with no any natural attenuation period ( 0 months) so raw SS considered highly contaminated, the lowest microorganisms biodiversity rates were 3 colonies which recorded after 12 months of natural attenuation. So our study on the count of microorganisms colonies supports the results obtained from the treatment of Vicia faba by SS extract that raw SS cannot be used as soil fertilizer because it has high percentage of toxicity which reduced through natural attenuation period sand reached to lowest percentage after 12 months compared by the reference soil which recorded only 3 colonies. Similar results reported by Petersen et al. (2003) they recorded microbial succession during decomposition of sewage sludge. Also, Mazzeo et al. (2015) recorded 17 different species of bacteria in addition to some fungi when they study the microorganisms succession in SS which decreased to 6 species after 12 months of natural attenuation. Many authors suggested that there are several types of bacteria in SS may have the ability to degrade contaminants that were initially present in these samples (Sharma et al., 2002).

\section{Detection of toxins}

Suzuki et al. (2011) recorded the existence of furans and dioxins in the environment; the occurrence of these compounds generally resulting from industrial activities such as incineration of halogenic substances, the ignition of diesel, the insecticides manufacture wood ignition and the microorganisms action. Klimm et al. (1998) also reported furans and dioxins existed in SS.

Using GC-MS analysis some toxins were identified in SS as furans in different levels which decreased with natural attenuation period increased which reflect the importance of natural attenuation for detoxification processes of raw SS to be available as a soil fertilizer. In our study, furans only were detected in about four forms and dioxins not detected at all (Table 2). Furan is an organic compound involving a five-membered aromatic ring with one oxygen and four carbon atoms. Furan derivatives are chemical compounds containing furan rings. Exposure to high levels of furans may rise the infection risk of rats and mice by hepatocellular tumors and tumors of the bile duct in rats. So furans recorded as a possible human carcinogen (Bakhiya and Appel, 2010). The reduction of toxins level across natural attenuation periods may be due to the microbial degradation as some study revealed that several microorganisms have been defined as degraders for dioxin and furan (Parsons et al., 1998; Suzuki et al., 2011).

\section{Conclusion}

Genotoxicity, cytotoxicity, and micronuclei in F1 cells of $V$. faba were induced owing to SS treatment for different natural attenuation periods, including different types of chromosomal abnormalities, which increased as the concentration of raw SS increased. However, this effect declined through the natural attenuation period. Regarding microorganisms progression of SS, six colonies were scored in row SS, but only three colonies remained after 12 months of natural attenuation. GC-MS analysis identified some toxins in SS as furans in different levels which decreased with natural attenuation period increased. Our study revealed that $V$. faba test can be used to evaluate the toxicity of SS contaminants. Also, raw SS is considered highly toxic and highly contaminated and cannot be used as soil fertilizer without natural attenuation for at least 6 months and must be mixed with soil to reduce its contamination to the 
environment and humans and so the application of SS in agriculture must be with caution. We recommended that, row SS needs more chemical and biological studies to identify all the contaminants in it and their impact on living organisms and the environment when it used as soil fertilizer.

Acknowledgments. The authors extend their appreciation to the Deanship of Scientific Research at King Khalid University for funding this work through the Research Project (RCAMS/KKU/003/20).

Conflict of interests. The author declares that they have no conflict of interests.

\section{REFERENCES}

[1] ABNT (Brazilian Association of Technical Standards) (2004): NBR 10006: Procedure to Obtain Solubilized Solid Waste Extract. - ABNT, Rio de Janeiro.

[2] ATSDR (Agency for Toxic Substances and Disease Registry) (2008): Toxicological Profile for Cresols. - ATSDR, Atlanta.

[3] Bakhiya, N., Appel, K. E. (2010): Toxicity and carcinogenicity of furan in human diet. Archives of Toxicology 84(7): 563-578. https://doi.org/10.1007/s00204-010-0531-y.

[4] Caritá, R. (2007): Evaluation of the Genotoxic and Mutagenic Potential of Samples from the Sewage Treatment Stations of Large Urban Centres in the State of São Paulo, Using Chromosomal Aberrations in Allium cepa. Monograph. - UNESP, Rio Claro.

[5] Christofoletti, C. A., Francisco, A., Fontanetti, C. S. (2012): Biosolid soil application: toxicity tests under laboratory conditions. - Applied and Environmental Soil Science 2012: 01-09.

[6] Clarke, B. O., Smith, S. R. (2011): Review of 'emerging' organic contaminants in biosolids and assessment of international research priorities for the agricultural use of bio-solids. - Environment International 37: 226-247.

[7] Crews, C., Castle, L. (2007): A review of the occurrence, formation and analysis of furan in heat-processed foods. - Trends in Food Science and Technology 18: 365-372.

[8] El-Shaboury, G. A., Haroun, S. A., Shaker, K., Badr, A. (2017): Systematics implications of GC-MS analysis of secondary metabolites in the ethanol extract of Solanum species from South West Saudi Arabia. - Egyptian Journal of Botany 57(2): 1-15.

[9] Fels, L. E., Hafidi, M., Vestre, J. S., Kallerhoff, J., Merlina, G., Pinelli, E. (2015): Efficiency of co-composting process to remove genotoxicity from sewage sludge contaminated with hexavalent chromium. - Ecological Engineering 82: 355-360.

[10] Gray, N. F. (2010): Sludge Treatment and Disposal. - In: Gray, N. F. (ed.) Water Technology an Introduction for Environmental Scientists and Engineers. ButterworthHeinemann, Oxford, pp. 645-685.

[11] Joulain, D., Koenig, W. A. (1998): The Atlas of Spectral Data of Sesquiterpene Hydrocarbons. - E. B. Verlag, Hamburg.

[12] Kapanen, A., Vikman, M., Rajasarkka, J., Virta, M., Itavaara, M. (2013): Biotests for environmental quality assessment of composted sewage sludge. - Waste Management 33: 1451-1460.

[13] Klimm, C., Schramm, K. W., Henkelmann, B., Martens, D., Kettrup, A. (1998): Formation of octa- and heptachloro dibenzo-p-dioxins during semi anaerobic digestion of sewage sludge. - Chemosphere 37: 2003-2011.

[14] Marcato-Romain, C. E., Guiresse, M., Cecchi, M., Cotelle, S., Pinelli, E. (2009): New direct contact approach to evaluate soil genotoxicity using the Vicia faba micronucleus test. - Chemosphere 77: 345-350. 
[15] Mazzeo, D. E. C., Levy, C. E., Angelis, D. F., Marin-Morales, M. A. (2010): BTEX biodegra-dation by bacteria from effluents of petroleum refinery. - Science of the Total Environment 47: 1255-1264.

[16] Mazzeo, D. E. C., Fernandesa, T. C. C., Levyb, C. E., Fontanettia, C. S., Marin-Moralesa, M. A. (2015): Monitoring the natural attenuation of a sewage sludge toxicity using the Allium cepa test. - Ecological Indicators 56: 60-69.

[17] Mesias, M., Morales, F. J. (2014): Analysis of Furan in Coffee. Chapter 110. - In: Preedy, V. R. (ed.) Coffee in Health and Disease Prevention. Elsevier, Amsterdam, pp. 1005-1011.

[18] Monarca, S., Rizzoni, M., Gustavino, B., Zani, C., Alberti, A., Feretti, D., Zerbini, I. (2003): Genotoxicity of surface water treated with different disinfectants using in situ plant tests. - Environmental and Molecular Mutagenesis 41: 353-359.

[19] Parsons, J. R., Bruijne, J. A., Weiland, A. R. (1998): Biodegradation pathway of 2chlorodibenzo-p-dioxin and 2-chlorodibenzofuran in the biphenyl-utilisingstrain JB1. Chemosphere 37: 1915-1922.

[20] Petersen, S. O., Henriksen, K., Mortensen, G. K., Krogh, P. H., Brandt, K. K., Sørensen, J., Madsen, T., Petersen, J., Grøn, C. (2003): Recycling of sewage sludge and household compost to arable land: fate and effects of organic contaminants, and impact on soil fertility. - Soil Tillage Research 72: 139-152.

[21] Sharma, A., Kachroo, D., Kumar, R. (2002): Time dependent influx and efflux of phenol by immobilized microbial consortium. - Environmental Monitoring Assessment 76: 195211.

[22] Shukla, O. P., Rai, U. N., Singh, N. K., Dubey, S., Baghel, V. S. (2007): Isolation and characterization of chromate resistant bacteria from tannery effluent. - Journal of Environmental Biology 28: 399-403.

[23] Souza, T. S., Hencklein, F. A., Angelis, D. F., Fontanetti, C. S. (2013): Clastogenicity of land farming soil treated with sugar cane vinasse. - Environmental Monitoring Assessment 185: 1627-1636.

[24] Srivastava, R., Kumar, D., Gupta, S. K. (2005): Bioremediation of municipal sludge by vermitechnology and toxicity assessment by Allium cepa. - Bioresource Technology 96: 1867-1871.

[25] Statsoft (2007): Statistica version 7.1. - Statsoft Inc, Tulsa, OK.

[26] Suzuki, Y., Nakamura, M., Otsuka, Y., Suzuki, N., Ohyma, K., Kawakami, T., Sato, K., Kajita, S., Hishiyama, S., Fujii, T., Takahashi, A., Katayama, Y. (2011): Novel enzymatic activity of cell extract from thermophilic Geobacillus sp, UZO 3 catalyses reductive cleavage of diaryl ether bonds of 2,7-dichorodibenzo-p-dioxin. - Chemosphere 83: 868872.

[27] Walter, I., Martínez, F., Cala, V. (2006): Heavy metal speciation and phytotoxic effects of three representative sewage sludge for agricultural uses. - Environmental Pollution 139: 507-514. 